\title{
Asynchronous left ventricular wall motion early after coronary thrombosis
}

\author{
DEREK GIBSON,† HELMUT MEHMET, * FRANZ SCHWARZ, * KUN LI, $\dagger$ \\ WOLFGANG KÜBLER*

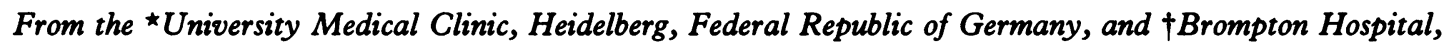 \\ London
}

SUMMARY To study regional wall motion early in the development of acute myocardial infarction, left ventriculograms performed in 24 patients before thrombolysis and within 3.5(1.2) (mean (SD)) hours of the onset of pain were digitised frame by frame. Isometric and contour plots of regional wall motion were constructed. In 19 patients (seven with anterior descending, eight with right, and four with circumflex disease) thrombosis was demonstrated on an underlying stenosis. In 10 patients the two remaining coronary arteries were normal, and in nine, one or both showed important disease. Mean values of global indices of left ventricular function, including end diastolic volume, ejection fraction, peak ejection and filling rates, and cavity shape changes were all within normal limits, though end systolic volume was significantly raised. Total systolic amplitude of wall motion was normal in the affected area in all but seven patients (four with anterior descending, two with right, and one with circumflex thrombosis). Dyskinesis of more than $2 \mathrm{~mm}$ was seen in only three patients, all with thrombosis of the anterior descending coronary artery, and hyperkinesis was present in four. The commonest abnormality of wall motion was hypokinesis during ejection followed by prolonged inward motion during isovolumic relaxation, which was seen in four patients with anterior descending, seven with right, and three with circumflex artery thrombosis. This was preceded by outward motion during isovolumic contraction and delayed inward motion during ejection in eight with right or circumflex thrombosis. Five of six patients without thrombosis had simple hypokinesis or dyskinesis without asynchrony. Disease of other coronary arteries did not affect the pattern of wall motion seen after right or circumflex coronary artery occlusion but it reduced the incidence of delayed inward motion along the free wall after thrombosis of anterior descending artery. Thus early after acute coronary thrombosis asynchronous wall motion is commoner than simple hypokinesis or dyskinesis. Its persistence suggests that in the setting of coronary artery thrombosis in man, residual contractile activity may persist for up to six hours after the onset of symptoms.

Selection of patients who are suitable for thrombolysis and acute revascularisation (for possible limitation of infarct size) is difficult. ${ }^{12}$ The aim is to identify those in whom there is important impairment of regional left ventricular function at a time when it is potentially reversible by reestablishment of coronary flow. Since myocardial function manifests itself in the amplitude and timing

Requests for reprints to Dr D G Gibson, Cardiac Department, Brompton Hospital, Fulham Road, London SW3 6HP.

Accepted for publication 10 September 1985 of wall motion, the present study was designed to examine left ventricular contrast angiograms of patients early after acute myocardial infarction with particular reference to detecting asynchronous regional wall movement. We hoped that this would provide a baseline for assessing the effects of procedures designed to limit infarct size and also that it would be possible to recognise patterns of motion which would identify regions where function was impaired but not irretrievably lost.

\section{Patients and methods}

Twenty four patients (aged 38-72 years) who 
fulfilled standard criteria as potential candidates for thrombolysis were studied at the University Hospital, Heidelberg. ${ }^{3}$ The study was performed $3 \cdot 5(1 \cdot 3)$ hours (mean (SD)) (range 0.5 to 7 hours) after the onset of symptoms. Left ventriculography was performed in the $30^{\circ}$ right anterior oblique projection as part of the clinical study. An injection of $40 \mathrm{ml}$ Urografin was given into the left ventricle at a flow rate of $12 \mathrm{ml} / \mathrm{s}$ through a pigtail catheter, and a cine film was exposed at 50 frames/s. Calibration was established from movement of the catheter tip positioned in the left ventricle when the table was displaced by $8 \mathrm{~cm}$. Ectopic and postectopic beats were not studied. Multiple views of the coronary arteries were then obtained by means of Judkins' technique.

\section{ANALYSIS OF ANGIOGRAMS}

Cavity outlines were digitised frame by frame over two beats in 18 of the patients and over a single beat for the remainder. ${ }^{4} \mathrm{~A}$ fixed external reference point on the margin of the cine frame was used throughout. The timing of aortic valve opening and closure at the start and end of ejection was established from direct inspection of the angiogram, from the frame on which each of these movements was complete. The timing of mitral valve opening was taken as that of the frame in which unopacified blood first appeared within the left ventricular cavity at the onset of diastole. Left ventricular ejection was taken as the interval between aortic valve opening and closure, and isovolumic relaxation as that between aortic closure and mitral opening.

From the digitised data, plots were made of superimposed endocardial cavity outlines-those from the start of the beat to the outline with the smallest area being taken as systolic and the remainder as diastolic. For each frame cavity volume was calculated ${ }^{5}$ and plotted as a continuous curve along with its first derivative from which peak rates of systolic and diastolic volume change were derived. The interval from mitral valve opening to the times of registration of peak filling rate and the end of rapid filling when the rate had dropped to $20 \%$ of its peak level was also noted. Shape index was calculated as $4 \pi \times$ area/(perimeter) ${ }^{2}{ }^{6}$ Ejection fraction was taken as stroke volume divided by end diastolic volume.

Regional wall motion was demonstrated by constructing isometric and contour plots for each beat. ${ }^{4}$ The method depends on multiple plots of wall motion against time, derived from $\mathbf{4 0}$ equally spaced points around the circumference of the end diastolic frame starting from the junction of the mitral valve with the aortic root. Segments 1-15 thus represent the inferior wall, 1-5 being the mitral valve, 15-25 the apical region, and 25-40 the free wall of the left ventricle. Regional wall motion was analysed either by stacking these individual plots obliquely to give an isometric display, or by constructing a series of contours representing $1 \mathrm{~mm}$ of inward or outward movement of endocardium from its position in the end diastolic frame. Examples are given in Figs. 1-4. Results from the patients were compared with those from 20 normal subjects with chest pain, normal ventricular haemodynamics, and coronary arteriograms. From these displays, the following information was derived.

(a) Segments in which the overall amplitude of inward motion during systole lay outside the $95 \%$ confidence limit of normal for the region in question were identified. Overall systole was here taken as extending from the time of maximum cavity area to the onset of mitral valve opening at the start of ventricular filling. When the amplitude of motion was below the lower $95 \%$ limit, the region was regarded as showing hypokinesis, and when it was greater than the upper $95 \%$ limit as showing hyperkinesis. Wall motion during ejection was considered in the same way. Dyskinesis was taken as outward motion of $2 \mathrm{~mm}$ or more occurring during ejection, lasting for at least $100 \mathrm{~ms}$. Specifically excluded from this definition was transient outward movement within $50 \mathrm{~ms}$ of aortic valve opening followed by inward motion later in ejection. This latter pattern was frequently seen in association with disturbances of isovolumic contraction.

(b) Segments showing abnormal wall motion early during systole. Two types were recognised. The first was abnormal ( $2 \mathrm{~mm}$ or more) outward movement of endocardium during isovolumic contraction and within the first $50 \mathrm{~ms}$ of ejection. ${ }^{7}$ The second was significant (more than $3 \mathrm{~mm}$ ) inward wall motion during isovolumic contraction.

(c) Segments showing abnormal inward movement during isovolumic relaxation of 2 or more $\mathrm{mm}^{3}$

(d) Outward motion of $7 \mathrm{~mm}$ or more during isovolumic relaxation involving segments 25-40 along the free wall. ${ }^{4}$

The extent of each abnormality was determined from the number of segments for which values lay outside the $95 \%$ confidence limits of normal. To study regional velocity of wall motion individual plots were identified on the anterior wall, at the apex, and on the inferior wall and displayed separately along with their first differential with respect to time. ${ }^{8}$ From this information the interval between maximum cavity area and peak rate of inward motion was plotted for each of the three segments together with the spread of values between them - that is the interval between the earliest and latest registration of the peak. Similarly, the timing of peak inward 
Table Overall left ventricular function

\begin{tabular}{|c|c|c|c|c|c|}
\hline & $\begin{array}{l}\text { Group } 1 \\
(n=10)\end{array}$ & $\begin{array}{l}\text { Group } 2 \\
(n=9)\end{array}$ & $\underset{(n=5)}{\text { Group }} 3$ & Reproducibility & $\begin{array}{l}\text { Normal } \\
(n=20)\end{array}$ \\
\hline $\begin{array}{l}\text { End diastolic volume }(\mathrm{ml}) \\
\text { End systolic volume (ml) } \\
\text { Ejection fraction }(\%) \\
\text { Peak ejection rate }(\mathrm{ml} / \mathrm{s}) \\
\text { Normalised ejection rate s } \\
\text { Peak filling rate }(\mathrm{ml} / \mathrm{s}) \\
\text { Normalised filling rate s } \\
\text { Shape change }(\%)\end{array}$ & $\begin{array}{l}190(66) \\
75(28) \\
64(7) \\
815(240) \\
3 \cdot 9(0 \cdot 6) \\
890(390) \\
4 \cdot 2(0 \cdot 8) \\
16(7)\end{array}$ & $\begin{array}{c}180(55) \\
70(45) \\
60(12) \\
560(135) \\
4 \cdot 0(1 \cdot 5) \\
480(180) \\
3 \cdot 5(1 \cdot 6) \\
13(8)\end{array}$ & $\begin{array}{c}190(80) \\
75(80) \\
65(29) \\
680(190) \\
3 \cdot 8(0 \cdot 9) \\
800(250) \\
4 \cdot 4(1 \cdot 1) \\
25(11)\end{array}$ & $\begin{array}{c}12 \\
6 \\
4 \\
110 \\
0 \cdot 6 \\
90 \\
0.5 \\
3\end{array}$ & $\begin{array}{l}150(35) \\
32(16) \\
66(7) \\
580(210) \\
4 \cdot 2(1 \cdot 1) \\
690(260) \\
4 \cdot 2(0 \cdot 7) \\
22(7)\end{array}$ \\
\hline
\end{tabular}

motion and the end of rapid outward motion when the velocity had fallen to $20 \%$ of its peak value were also measured for each segment with respect to the timing of mitral valve opening along with the spread of each between segments. Regions in which the overall amplitude of motion was $4 \mathrm{~mm}$ or less were not studied, because the first derivatives consistently failed to show the normal configuration during ejection and filling and these measurements could not be made.

\section{ANALYSIS OF CORONARY ARTERIOGRAMS}

Coronary arteriograms were examined when the analysis of wall motion was complete. In 19 of the patients, one coronary artery was found to be completely obstructed. The cut off of contrast was sharp, and when streptokinase was infused a lumen was re-established. Such an obstruction was taken as being due to thrombus, and the affected artery was noted. The extent of the remaining coronary artery disease was also recorded. From this information it was possible to divide the patients into three groups: group 1-those in whom there was occlusion of a single coronary artery by thrombus, the other two vessels either being normal or showing no more than a trivial stenosis; group 2-those in whom there was occlusion of a single coronary artery by thrombus, but an important (more than $75 \%$ ) lesion of one or both of the remaining arteries; and group 3-those in whom no thrombus could be identified but in whom coronary artery disease was present. Groups 1 and 2 were further subdivided according to which of the three main coronary arteries was affected by the thrombus.

\section{STATISTICAL METHODS}

Student's $t$ test was used to compare differences

(a)
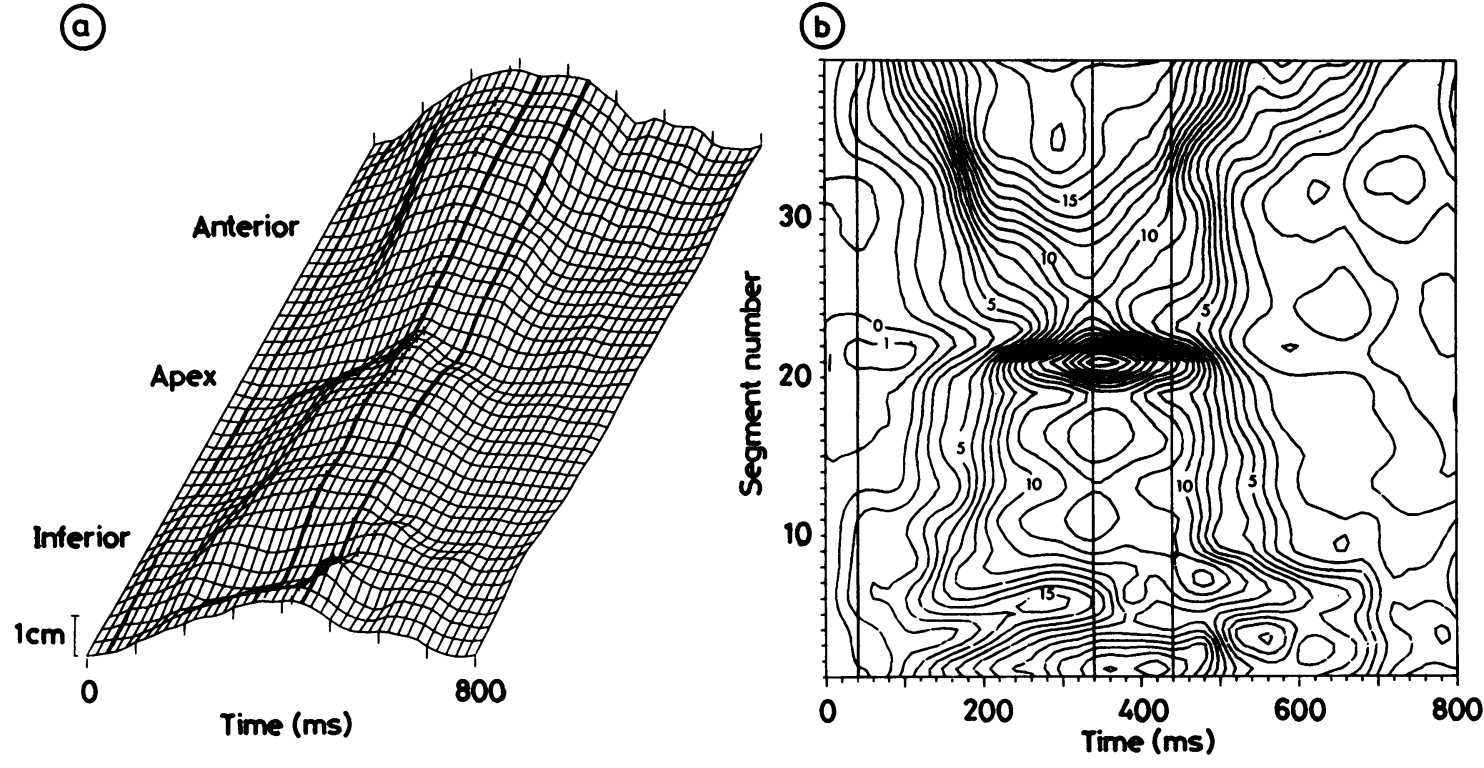

Fig. 1 (a) Isometric plot of normal angiogram. Accentuated time markers (isochrones) represent aortic opening, aortic closure, and mitral opening, respectively. The pattern of wall motion is synchronous except in the most inferior segments where mitral valve motion is recorded. (b) Contour plot of data from Fig. 1 a. 
between mean values. Reproducibility of measures of overall left ventricular function was established from measurements made in 18 patients in whom two beats were of adequate technical quality for digitisation; this was determined as the root mean square of the difference between the two determinations.

\section{Results}

\section{DISTRIBUTION OF LESIONS}

Thrombosis of one coronary artery was demonstrated in 19 patients. Ten of them had no important disease elsewhere in the coronary tree (group 1), the thrombosis being in the anterior descending in three, in the circumflex in two, and in the right coronary artery in five patients. Of the remainder, in whom there was important disease elsewhere (group 2), the thrombosis was in the anterior descending in four, the right in three, and the circumflex in two. In the remaining five patients, no clear thrombosis was demonstrated (group 3); however, important disease of anterior descending alone was present in three, anterior descending and circumflex in one, and left main stem disease in one.

OVERALL LEFT VENTRICULAR FUNCTION

The Table gives measurements of overall left ventricular function for the three groups of patients together with normal values and estimates of reproducibility from paired determinations. Values of end systolic volume were significantly greater than normal in groups 1 and $2(p<0.05)$, but otherwise mean values did not differ significantly from normal, or from one another. In several cases, however, values outside the $95 \%$ confidence limits of normal were seen. These included seven in whom end diastolic volume was greater than the upper limit of normal, four in group 1, two in group 2, and one in group 3. End systolic volume lay outside the normal range in six cases in group 1, three in group 2, and one in group 3. Ejection fraction was below normal in only three patients, one in each group. Values of peak ejection were within the wide limits of normal in all patients, but peak normalised filling rate was low in four patients, three in group 2 and one in group 3; depression in group 2 was statistically significant compared with normal $(p<0.05)$. The extent of overall shape change during the cardiac cycle was also within normal limits in all except four patients, one in group 1 and three in group 2.

\section{REGIONAL LEFT VENTRICULAR FUNCTION}

Fig. 1 gives examples of isometric and contour displays from a normal subject. On the isometric

(a)
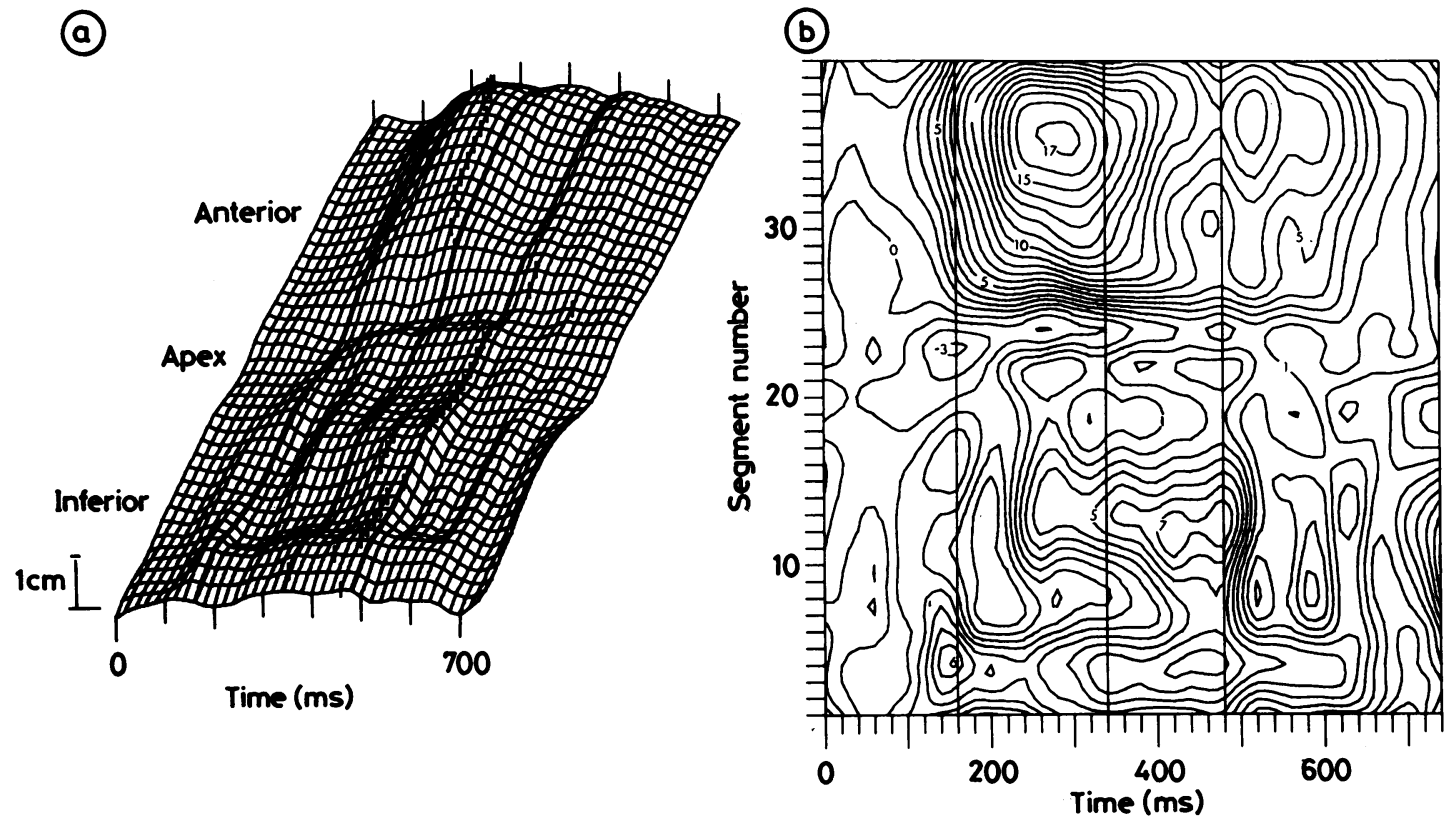

Fig. 2 (a) Isometric plot of angiogram from a patient with recent right coronary artery thrombosis. Layout as in Fig. 1. There is abnormal outward motion during isovolumic contraction followed by prolonged inward motion along the inferior wall during isovolumic relaxation. On the free wall there is abnormal outward movement during isovolumic relaxation. (b) Contour plot of data from Fig. $2 b$. 
displays from a normal subject. On the isometric display the horizontal lines represent the 40 original plots of wall movement against time, inward displacement being represented as an upward deviation. The diagonal lines, isochrones, join events occurring simultaneously on the 40 plots. The three accentuated isochrones represent the timing of aortic opening, aortic closure, and mitral opening. The position in the ventricle from which the plots are derived is shown on the left. The contour display is derived from the same information. Each contour represents $1 \mathrm{~mm}$ of inward or outward motion of endocardium from its position in the end diastolic frame. The three vertical lines again correspond to aortic opening, aortic closure, and mitral opening. In the normal subject, there is no significant wall motion before aortic valve opening. During ejection, there is synchronous inward movement of endocardium, shown by the contour lines being almost vertical except towards the apex. On the free wall outward motion starts during isovolumic relaxation and precedes that at the apex or on the inferior wall. After mitral valve opening, movement is rapid and synchronous as shown by the closely spaced and vertical contour lines.
RIGHT CORONARY ARTERY THROMBOSIS

The right coronary artery was occluded by thrombus in eight patients, three of whom had important disease elsewhere (Fig. 2a and b). The general direction of wall motion can be appreciated on the isometric plot (Fig. 2a), and the extent and localisation of any abnormality quantified from the contour display (Fig. 2b). Wall motion is abnormal in all regions of the ventricle. On the inferior wall there is $3 \mathrm{~mm}$ outward motion before and immediately after aortic valve opening over segments $5-10$. Inward wall motion then occurs, but it is delayed and continues throughout isovolumic relaxation, when $3-4 \mathrm{~mm}$ further inward movement is seen along the entire inferior wall. The overall amplitude of inward motion is thus $9-10 \mathrm{~mm}$, well within the $95 \%$ confidence limits of normal, although only $4 \mathrm{~mm}$ of this occurs during ejection. At the apex, there is akinesis (segments 22-25). Overall amplitude of motion is normal along the free wall, but inward motion starts before aortic valve opening $(5 \mathrm{~mm}$ in segments 33-40). In addition, during isovolumic relaxation there is $10 \mathrm{~mm}$ outward motion from segments 27-35.

(a)
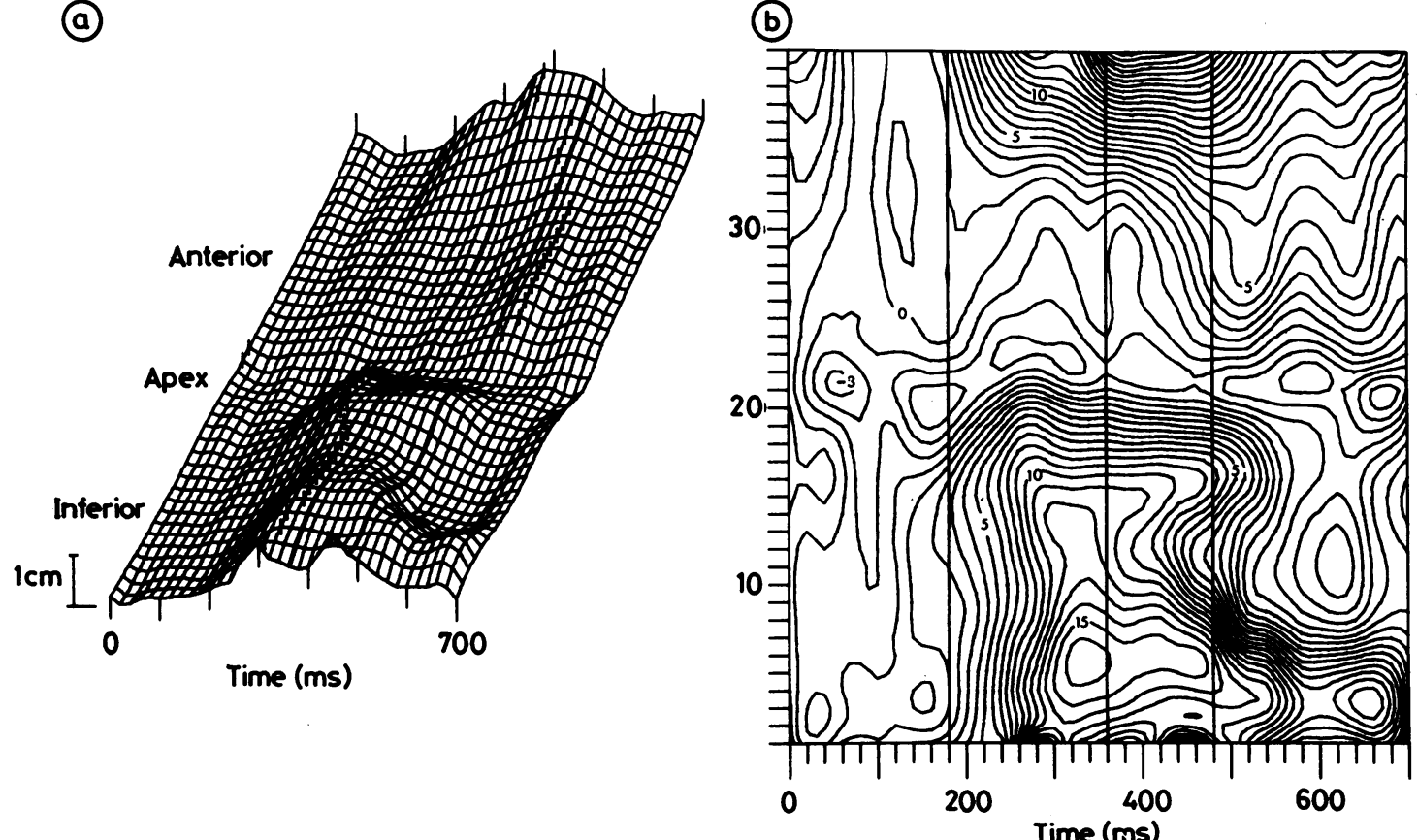

Fig. 3 (a) Isometric plot of angiogram from a patient with recent anterior descending thrombosis. Movement on the inferior wall is normal, but on the free wall there is dyskinesis during the first half of ejection followed by delayed inward motion of $5 \mathrm{~mm}$ reaching a peak at the time of mitral opening. (b) Contour plot of data from Fig. $3 a$. 
In the group as a whole, the inferior wall was hypokinetic in only two, one of whom had an ejection fraction of $33 \%$, while in the remainder the overall amplitude of inferior wall motion was within normal limits. Dyskinesis was not seen in any patient with right coronary artery thrombosis. On the free wall the amplitude of wall motion was increased in two patients to 23 and $24 \mathrm{~mm}$ (both in group 1) and was normal in the remainder. During ejection values were low (between 2 and $4 \mathrm{~mm}$ on the inferior wall in seven patients) and segments 10 (2) to 17 (3) (mean (1 SD)) were affected in group 1 and 5(1) to 13(3) in group 2. The difference between the overall amplitude of motion and that during ejection reflected abnormal movement during the two isovolumic periods. In six out of the eight patients this occurred during isovolumic contraction and early ejection and affected segments 9 (3) to 15(3). At the same time, early inward movement of endocardium of $4-8 \mathrm{~mm}$ occurred in six patients in the anterior region of the cavity before aortic valve opening, confirming that cavity shape was changing during isovolumic contraction. Wall movement during isovolumic relaxation was also disturbed, with abnormal inward motion of 2 to $4 \mathrm{~mm}$ in segments 8 (3) to 12 (2) being recorded in seven of the eight patients. At the same time, abnormal outward movement of 9-13 mm occurred along the free wall in three patients followed by abnormal inward movement during filling in one. Filling was incoordinate, with the timing of peak rate of outward motion showing a mean spread of $105(70) \mathrm{ms}$ between segments (normal $40(20) \mathrm{ms}$ ), though that of the end of filling $(45(30) \mathrm{ms}$ ) was not significantly different from normal (43(20)). Peak rate of outward motion along the free wall frequently occurred before mitral valve opening (mean 10(70) $\mathrm{ms}$ ), while that at the apex followed it by $35(50) \mathrm{ms}$ and on the inferior wall by $105(70) \mathrm{ms}$. The corresponding figures for normal are $40(30), 40(30)$, and 40 (25) $\mathrm{ms}$ after mitral valve opening for the anterior, apical, and inferior regions respectively.

\section{ANTERIOR DESCENDING CORONARY ARTERY THROMBOSIS}

The pattern of free wall motion after thrombosis of the anterior descending coronary artery was similar but not identical to that on the inferior wall after thrombosis of the right coronary artery (Fig. 3a and b). Here wall motion is very abnormal, particularly between segments 24 and 33 where there is $2 \mathrm{~mm}$ dyskinesis during ejection. This is followed by inward movement, starting late in ejection and continuing throughout isovolumic relaxation to reach a maximum at the time of mitral valve opening. Normal outward movement is seen during filling. The overall amplitude of inward movement is $7 \mathrm{~mm}$, well

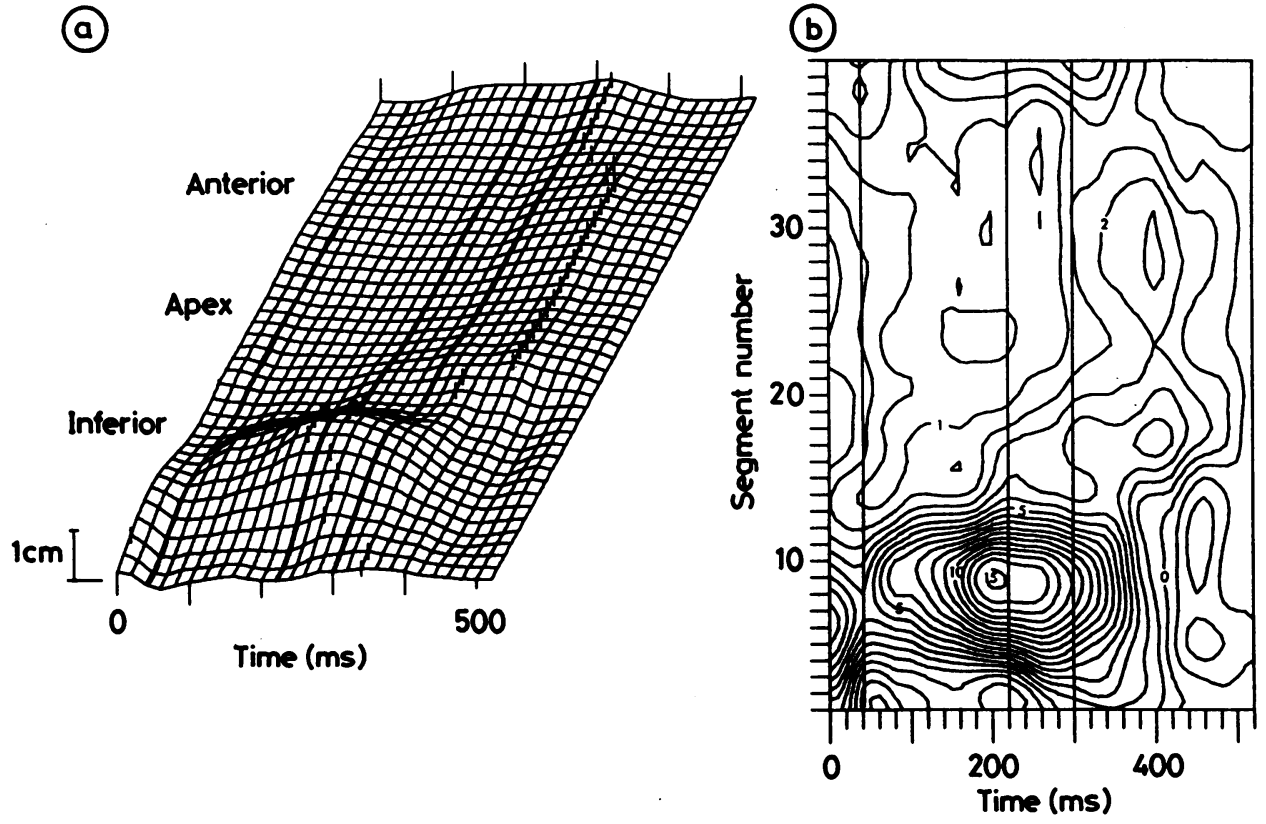

Fig. 4 (a) Isometric plot of angiogram from a patient with chronic anterior descending and circumflex disease but without evidence of thrombosis. Inferior wall motion is normal but apex and free wall are akinetic. There is no evidence of residual contractile activity. (b) Contour plot of data from Fig. $4 a$. 
within the normal range for this region. Wall motion in the inferior part of the cavity is normal, both with respect to amplitude and to its time relations, and rapid outward motion of endocardium during ventricular filling is preserved. Thrombosis of the anterior descending coronary artery was seen in seven patients, four of whom had important disease of the other coronary arteries. A reduction in the overall amplitude of systolic wall motion was present at the apex in four patients and also affected the free wall in three. Important hypokinesis was seen during ejection in all. It was maximum along the anterior free wall and at the apex from segments 15(2) to 25 (3). Its distribution was unaffected by the presence or absence of disease of the other coronary arteries. Dyskinesis of 2 to $5 \mathrm{~mm}$ was seen in two patients, involving segments $22-29$ and $25-29$, that caused an increase to $110(50) \mathrm{ms}$ in the time interval over which peak rate of inward movement occurred $(p<0.01$, compared with normal). An increase in the amplitude of inferior wall motion to $19 \mathrm{~mm}$ was seen in one patient. As after right coronary occlusion, the time relations of this hyperkinetic motion were normal. During isovolumic contraction there was no evidence of the early outward motion of endocardium on the free wall resembling that seen along the inferior wall after right coronary artery occlusion. During isovolumic relaxation, however, inward motion of 3-5 $\mathrm{mm}$ was seen in each of the three patients with isolated anterior descending coronary artery disease (segments 23-35, 23-31, and 22-30) and in one of five in group 2. During filling, outward wall motion was not incoordinate, as it was in patients with inferior infarction; the normal pattern was preserved with peak outward movement following mitral valve opening at all three sites. The spread of the timing of both the peak and the end of rapid outward motion between regions was also normal.

\section{CIRCUMFLEX CORONARY ARTERY}

THROMBOSIS

The disturbance to wall motion after circumflex occlusion closely resembled that after occlusion of the right coronary artery. Overall amplitude of inferior wall motion was low in one of the four patients. During ejection it was reduced in all to $2-4 \mathrm{~mm}$, over segments 8(3) to 15 (2). Dyskinesis was not seen. In two patients there was synchronous hyperkinesis of the anterior wall $(19 \mathrm{~mm}$ and $21 \mathrm{~mm}$ ). Abnormal outward movement of $3 \mathrm{~mm}$ during isovolumic contraction was present in two patients in segments 14-18 and 17-20, and there was abnormal inward movement of the free wall of $6 \mathrm{~mm}$ in one. In three patients there was prolonged inward motion during isovolumic relaxation of 3-6 along the inferior wall; one of them also showed $16 \mathrm{~mm}$ early outward move- ment on the anterior wall. The spread in the timing of the peak and end of rapid filling were $70(75) \mathrm{ms}$, and $120(50) \mathrm{ms}$ respectively, considerably greater than normal, although the difference was not statistically significant at a sample size of four. No difference in the pattern of wall movement was present between the patients in group 1 and those in group 2.

\section{PATIENTS WITHOUT DEMONSTRABLE THROMBOSIS}

These patients demonstrated various disturbances of wall motion. All the four patients with important disease of the left anterior descending coronary artery had hypokinesis affecting the free wall, and in one there was dyskinesis of $2 \mathrm{~mm}$ affecting segments 22-26. An example is given in Fig. 4a and b. Here, there is a very extensive area of akinesis covering segments 14-40. Wall motion along the inferior wall is normal, both with respect to amplitude and also timing, with no disturbance during isovolumic contraction or relaxation. There is no disturbance of wall motion over the remainder of the ventricle.

Only one patient (with left main stem disease) showed early outward movement of endocardium at the apex (18-22), and none had any abnormality of wall motion during isovolumic relaxation. A patient with anterior descending coronary artery disease showed an increase in the amplitude of inferior wall motion to $22 \mathrm{~mm}$, while in the remainder it was normal.

\section{Discussion}

Impairment of left ventricular function is a major cause of disability and death after acute coronary occlusion, and early and late mortality can be shown to be closely related to the extent of infarcted myocardium. ${ }^{910}$ The advent of procedures for revascularisation has altered the natural history of coronary thrombosis, so that the development of myocardial infarction in the absence of an adequate collateral flow is no longer inevitable. It seems reasonable to postulate a phase of partial loss before irreversible loss of function occurs. This might be termed impending myocardial infarction. Although there is no definite evidence for its existence in man, it might be recognisable from a pattern of wall motion intermediate between normal and one that is wholly passive. Experimental studies suggest that the main characteristics of such wall motion might be a reduction in peak force and prolongation of tension development, with significant myocardial shortening occurring only as ventricular pressure falls at the end of ejection. ${ }^{11}$ Contrast angiography is a particularly suitable method for studying regional wall motion in 
man. Its resolution in space is considerably superior to that of cross sectional echocardiography or radionuclide angiography, and frame rates of 50/s are readily attained. Because it is an invasive technique its use is necessarily limited, but when records are already being obtained as part of the clinical management of patients it seems desirable to extract the maximum information from them. We digitised all the frames in each cardiac cycle in order to study asynchronous wall motion rather than only those at end diastole and end systole, as in previous studies in which wall motion was analysed after acute myocardial infarction. ${ }^{1213}$ This proved to be essential if partial loss of function was to be detected. It also allowed us to avoid errors in the quantification of regional wall motion associated with use of only two frames. ${ }^{14}$

Although all the patients studied had evidence of impending myocardial infarction, overall measures of left ventricular function were usually normal. This applied not only to ventricular volumes and ejection fraction, but also to peak ejection and filling rates. For all these quantities, estimates outside the $95 \%$ confidence limits of normal were seen in only a few cases, and it was striking that all could be within normal limits in patients with severe disturbances of regional motion. Our observations thus extend those of Sheehan et $\mathrm{al}^{15}$ in demonstrating the relative insensitivity of these overall measurements of left ventricular function in detecting the effects of impending myocardial infarction.

The original experiments of Tennant and Wiggers in animals showed that regional akinesis or dyskinesis was a specific feature of acute coronary artery occlusion. ${ }^{16}$ Similar findings have been demonstrated by cross sectional echocardiography after acute myocardial infarction in man. ${ }^{17-19}$ These studies were based on subjective examination of video tapes; normal limits for regional wall motion were not defined nor was the possibility of asynchrony considered. Regional hypokinesis has also been demonstrated angiographically by shortening of hemicords, ${ }^{20}$ subjective wall motion scores, ${ }^{21}$ reduction in regional ejection fraction, ${ }^{22}$ or use of multiple plots derived by the "center line" technique. ${ }^{23}$ Unlike these previous studies, we found the incidence of overall hypokinesis to be low in regions supplied by occluded coronary arteries. In part this arose from our use of $95 \%$ confidence limits. These are wide, making the definition of hypokinesis a strict one. The main reason, however, for the discrepancy was that appreciable wall motion also occurred during the two isovolumic periods, so that the inward component during ejection was reduced despite the overall amplitude being within normal limits. The distribution of hypokinesis during ejection corresponded closely with that of the affected artery as demonstrated by the right anterior oblique projection. Dyskinesis was less common and occurred in only three patients all of whom had occlusion of the anterior descending coronary artery.

Asynchrony was the most common disturbance of wall motion in the first few hours after coronary occlusion. Several manifestations could be recognised. In the territory of the occluded coronary artery the commonest disturbance was considerable inward motion of endocardium during isovolumic relaxation instead of the slight outward motion usually seen in normal individuals. This inward motion reached its peak at the time of mitral valve opening. When the thrombus affected the right or circumflex coronary artery we also noted abnormal outward endocardial motion of $2 \mathrm{~mm}$ or more along the inferior wall during isovolumic contraction and early ejection followed by inward motion later in ejection, which usually continued until aortic valve closure to merge with inward motion during isovolumic relaxation. Associated with these disturbances in the region supplied by the occluded coronary artery, distant abnormalities were also seen, again in the two isovolumic periods. Early outward motion of the inferior wall during isovolumic contraction was associated with abnormal inward movement of the free wall before aortic valve opening. Similarly, prolonged inward motion during isovolumic relaxation of the inferior wall was associated with early outward motion of the free wall, often amounting to $10 \mathrm{~mm}$ or more by the time of mitral valve opening, previously referred to as SERP (segmental early relaxation phenomenon. ${ }^{24}$ Both these latter disturbances appear to be manifestations of an overall change in cavity shape at a time of constant cardiac volume and so result directly from changes in the ischaemic area. It is not necessary to postulate any additional mechanism such as ischaemia at a distance from the original infarct to explain them.

Detailed analysis of these abnormalities of wall motion demonstrated important differences in pattern depending on the position of the affected myocardium within the ventricle. Thus, outward motion during isovolumic contraction did not occur on the free wall after thrombosis of the anterior descending coronary artery as it did on the inferior wall after that of the right or circumflex. True dyskinesis, that is outward motion of endocardium throughout ejection, was seen only on the anterior wall and not along the inferior wall in any of the eight cases with right coronary artery occlusion. In addition, delayed inward movement during isovolumic relaxation occurred on the inferior wall after right coronary artery occlusion whether or not other coronary arteries were affected; while on the anterior wall it was seen 
only with isolated left coronary artery occlusion and not when other vessels were affected. Finally, outward motion of endocardium during isovolumic contraction occurred almost exclusively on the free wall after right or circumflex coronary thrombosis but not on the inferior wall after occlusion of the anterior descending coronary artery. Dependence of the pattern of wall motion on the region of the ventricle affected as well as on the coronary arteries affected also occurs in patients with chronic coronary artery disease so the precedent for variation of this sort is clearly established. ${ }^{25}$

These complex abnormalities in the timing of wall motion cannot be explained on the basis of simple movement of the heart in space. The possibility arises that they might be due to tethering, ${ }^{26} \mathrm{im}$ plying that affected myocardium shows no appreciable intrinsic contractile activity and that any motion is passive and due to the physical proximity of a normally functioning region. This mechanism is incompatible with the unique phase relations of the affected areas, which differ both from normal and akinetic myocardium. If myocardium in affected areas behaved in a purely passive manner it would move outwards with systolic tension development and inwards again with the onset of diastole. Although outward motion did indeed occur during isovolumic contraction and early ejection as would be expected from simple passive behaviour, inward motion during late ejection before aortic valve closure is incompatible with this mechanism. Similarly, inward motion of these areas continued only during isovolumic relaxation, and was reversed during rapid filling at a time when ventricular pressure continued to fall, again a feature incompatible with purely passive behaviour. The likeliest explanation seems to be that residual contractile activity persists in these affected regions. In most instances such areas showed delayed inward wall motion during isovolumic relaxation, when ventricular pressure is likely to have been falling and the wall stress was thus lower than that during ejection. Such delayed and reduced contraction has been observed experimentally with hypoxia ${ }^{11}$ and after reperfusion. ${ }^{2728}$ The pattern of regional wall motion thus suggests that the functional disturbance caused by coronary thrombosis in man may differ from that due to acute occlusion in animal models, and that it is incompatible with that predicted on the basis of purely passive behaviour. This is probably because coronary artery thrombosis usually occurs in the setting of coronary artery disease, with affected arteries being the seat of pre-existing stenosis. Adaptive changes in the distal vascular bed can thus be postulated, in particular the development of collateral flow. Whatever the mechanism, it seems that in most cases presenting within six hours of the onset of the clinical syndrome of impending myocardial infarction a pattern of wall motion compatible with the persistence of some contractile activity can still be demonstrated in the territory of the affected artery, a finding that may well have clinical relevance when the feasibility of limiting the extent of ischaemic damage is considered.

These results may be of clinical value in assessing the effects of thrombolysis or other procedures designed to increase coronary flow immediately after acute coronary occlusion. They strongly suggest that using ejection fraction or other indices of overall left ventricular function is likely to prove unfruitful, since these measurements are so often normal in the control state. Regional wall motion must thus be studied, but to confine observations simply to its amplitude between frames arbitrarily defined as end diastolic and end systolic is likely to prove misleading. Its timing must also be documented. This not only allows errors associated with the two frame technique to be avoided, but also makes it possible to locate and quantify regions whose behaviour strongly suggests impairment but not loss of contractile activity. This information is potentially available non-invasively in man, for example from cross sectional echocardiography using appropriate methods of analysis and display, ${ }^{29} 30$ or from digital subtraction angiography. This might allow the process of patient selection for treatment designed to limit damage caused by infarction to be refined, and also might aid in the assessment of recently introduced procedures such as intravenous thrombolysis.

\section{References}

1 Laffel GL, Braunwald E. Thrombolytic therapy. A new strategy for the treatment of acute myocardial infarction (First of two parts). N Engl $\mathcal{f}$ Med 1984; 311: 710-7.

2 Rentrop KP, Cohen M, Hosat ST. Thrombolytic therapy in acute myocardial infarction: review of clinical trials. Am $\mathcal{f}$ Cardiol 1984; 54: 29-31E.

3 Schwarz F, Schuler G, Katus H, et al. Intracoronary thrombolysis in acute myocardial infarction: duration of ischemia as a major determinant of late results after recanalization. Am $\mathcal{f}$ Cardiol 1982; 50: 933-7.

4 Gibson DG, Prewitt TA, Brown DJ. Analysis of left ventricular wall movement during isovolumic relaxation and its relation to coronary artery disease. $\mathrm{Br}$ Heart $\mathcal{F}$ 1976; 38: 1010-9.

5 Sandler H, Dodge HT. The use of single plane angiocardiograms for the calculation of left ventricular volume in man. Am Heart $\mathcal{f} 1968$; 75: 325-34.

6 Gibson DG, Brown DJ. Continuous assessment of left ventricular shape in man. Br Heart $\mathcal{F} 1975$; 37: 904-10.

7 Gibson DG, Doran JH, Traill TA, Brown DJ. Abnormal left ventricular wall movement during early systole in patients with angina pectoris. Br Heart $\mathcal{f} 1978$; 40: 758-66. 
8 Hui WKK, Lee PK, Chow JSF, Gibson DG. Analysis of regional left ventricular wall motion during diastole in mitral stenosis. Br Heart $\mathcal{F}$ 1983; 50: 231-9.

9 Sobel BE, Bresnahan GF, Shell WE, Yoder RD. Estimation of infarct size in man and its relation to prognosis. Circulation 1972; 46: 640-8.

10 Herlitz J, Hjalmarson A, Waldenström J. Correlation between enzymatic estimation of infarct size and early mortality rate. Br Heart f 1983; 50: 520-4.

11 Tyberg JV, Parmley WW, Sonnenblick EH. In-vitro studies of myocardial asynchrony and regional hypoxia. Circ Res 1969; 25: 569-79.

12 Rigaud M, Rocha P, Boschat J, Farcot JC, Bardet J, Bourdarias JP. Regional left ventricular function assessed by contrast angiography in acute myocardial infarction. Circulation 1979; 60: 130-9.

13 Bertrand ME, Rousseau MF, Lablanche JM, Carre AG, LeKieffre JP. Cineangiographic assessment of left ventricular function in the acute phase of transmural myocardial infarction. Am $\mathcal{F}$ Cardiol 1979; 43: 472-80.

14 Gibson DG, Marier DL. Limitations of two frame method for displaying regional left ventricular wall motion. Br Heart $\mathcal{9}$ 1980; 44: 555-9.

15 Sheehan FH, Szente A, Matthey DG, Dodge HT. Discordance between ejection fraction and regional hypokinesis in acute and chronic myocardial infarction [Abstract]. I Am Coll Cardiol 1984; 3: 527.

16 Tennant $R$, Wiggers CJ. The effect of coronary occlusion on myocardial contraction. Am F Physiol 1935; 112: $351-61$.

17 Nixon JV, Narahara KA, Smitherman TC. Estimation of myocardial involvement in patients with acute myocardial infarction by two-dimensional echocardiography. Circulation 1980; 62: 1248-55.

18 Visser CA, Kan G, Lie KI, Becker AE, Durrer D. Apex two dimensional echocardiography: alternative approach to quantification of acute myocardial infarction. Br Heart f 1982; 47: 461-7.

19 Heger JJ, Weyman E, Wann LS, et al. Cross-sectional echocardiographic analysis of the extent of left ventricular asynergy in acute myocardial infarction. Circulation 1980; 61: 1113-8.
20 Spann JF, Sherry S, Carabello BA, et al. Coronary thrombolysis by intravenous streptokinase in acute myocardial infarction: acute and follow-up studies. $\mathbf{A m}$ f Cardiol 1984; 53: 655-61.

21 De Feyter PJ, van Eenige MJ, van der Wall EE, et al. Effects of spontaneous and streptokinase-induced recanalization on left ventricular function after myocardial infarction. Circulation 1983; 67: 1039-44.

22 de Wood MA, Heit J, Spores J, et al. Anterior transmural myocardial infarction: effects of surgical coronary reperfusion on global and regional left ventricular function. I Am Coll Cardiol 1983; 1: 1223-34.

23 Sheehan FH, Mathey DG, Schofer J, Krebber HJ, Dodge HT. Effect of interventions in salvaging left ventricular function in acute myocardial infarction: a study of intracoronary streptokinase. Am $\mathcal{F}$ Cardiol 1983; 52: 431-8.

24 Altieri PI, Wilt SM, Leighton RF. Left ventricular wall motion during the isovolumic relaxation period. Circulation 1973; 48: 499-505.

25 Greenbaum RA, Gibson DG. Regional non-uniformity of left ventricular wall movement in man. Br Heart $\mathcal{f}$ 1981; 45: 29-34.

26 Weiss JL, Bulkley BH, Hutchins GM, Mason SJ. Twodimensional echocardiographic recognition of myocardial injury in man: comparison with postmortem studies. Circulation 1981; 63: 401-8.

27 Theroux P, Ross J Jr, Franklin D, Covell JW, Bloor CM, Sasayama S. Regional myocardial function and dimensions early and late after myocardial infarction in the unanesthetized dog. Circ Res 1977; 40: 158-65.

28 Weiner JM, Apstein CS, Arthur JH, Pirzada FA, Hood WB Jr. Persistence of myocardial injury following brief periods of coronary occlusion. Cardiovasc Res 1976; 10: 678-86.

29 Gibson DG, Brown DJ, Logan-Sinclair RB. Analysis of regional left ventricular wall movement by phased array echocardiography. Br Heart $\mathcal{F}$ 1978; 40: 1334-8.

30 Weyman AE, Franklin TD Jr, Hogan RD, et al. Importance of temporal heterogeneity in assessing the contraction abnormalities associated with acute myocardial ischemia. Circulation 1984; 70: 102-12. 
in our patient who was closely monitored, but it is possible that a proportion of sudden deaths in anaphylaxis without respiratory manifestations could be due to serious rhythm disturbances related to QT prolongation. Routine electrocardiographic monitoring of the patients surviving immediate anaphylaxis would help in identifying electrocardiographic and rhythm disturbances.

\section{References}

1 Simmonds J, Hodges S, Nichol F, Barnett D. Anaphylaxis after oral penicillin. $\mathrm{Br}$ Med $\mathcal{F}$ 1978; ii: 1404 .

2 Petsas AA, Kotler MN. Electrocardiographic changes associated with penicillin anaphylaxis. Chest 1973; 64: 66-9.

3 Bernreiter M. Electrocardiogram of patients in anaphylactic shock. fAMA 1959; 170: 1629-30.

4 Booth BH, Patterson R. Electrocardiographic changes during human anaphylaxis. $\mathfrak{F} A M A$ 1970; 211: 627-31.

5 Patterson R, Fink JN, Winnemak J, Baum J, Prazensky $\mathrm{J}$, Nistrimurce ET. The biological consequences of the immediate type hypersensitivity transferred from man to monkey. $\mathcal{F}$ Allergy 1966; 37: 295-310.

6 Delage C, Irey NS. Anaphylactic deaths: a clinicopathologic study of 43 cases. I Forensic Sci 1972; 17: 525-40.

7 Surawicz B, Knoebel SB. Long QT: good, bad or indifference? f Am Coll Cardiol 1984; 4: 398-413.

8 Abildskov JA. Adrenergic effects on the QT interval of the electrocardiogram. Am Heart $\mathcal{1}$ 1976; 92: 210-6.

9 Lepeschkin E. Myocarditis in acute infections and allergic states. In: Modern electrocardiography. Vol I. Baltimore: The Williams and Wilkins Company, 1951: 459-74.

10 Lepeschkin E. Chemical pharmacological and toxicological influences. In: Modern electrocardiography. Vol I. Baltimore: The Williams and Wilkins Company, 1951: 282-311.

11 Yanowitz F, Preston JB, Abildskov JA. Functional distribution of right and left stellate innervation to the ventricles: production of neurogenic electrocardiographic changes by unilateral alteration of sympathetic tone. Circ Res 1966; 18: 416-28.

12 Surawicz B. Electrocardiographic pattern of cerebrovascular accident. $\mathcal{f A M A} 1966$; 197: 913-4.

\section{Notice}

\section{British Cardiac Society}

The Annual General Meeting for 1986 will take place in York on 2 and 3 April 1986, and the closing date for receipt of abstracts was 2 January 1986.

The Autumn Meeting will be held at the Wembley Conference Centre, London, on 25 to 27 November 1986, and the closing date for receipt of abstracts will be 1 August 1986.

\section{Correction}

Asynchronous left ventricular wall motion early after coronary thrombosis D Gibson, $H$ Mehmel, $F$ Schwarz, $K L i, W$ Kübler - We apologise to $\mathrm{Dr}$ Helmuth Mehmel for the misspelling of his name in our January issue (page 4). 